\title{
Google maps showing international coauthor collaborations for journal articles on physiotherapy
}

\author{
Tsair-Wei Chien ${ }^{1,2}$ Yu Chang ${ }^{3}$ and Chun- Ming Yang ${ }^{4 *}$ \\ ${ }^{1}$ Research Departments, Chi-Mei Medical Center, Taiwan \\ ${ }^{2}$ Department of Hospital and Health Care Administration, Chia-Nan University of Pharmacy and Science, Tainan, Taiwan \\ ${ }^{3}$ National Taiwan University School of Medicine \\ ${ }^{4}$ Holistic Care Unit of Chi-Mei Medical Center, Tainan, Taiwan
}

\begin{abstract}
Purpose: Identifying international coauthor collaborations for journal papers on physiotherapy is important and meaningful. However, no any paper that can combine Google map and Social Network Analysis (SNA) to present valuable information for readers. Our aims were to visualize the feature of international coauthor collaborations on the topic of physiotherapy and present the result on a Google map using SNA.

Methods: Downloading 3342 articles on November 5, 2017 from Pbumed.com, we analyzed author nation and report features: (1) nations published the most papers in physiotherapy; (2) the prominent journal published the most papers in physiotherapy; (3) visual representations to report the cluster relations in physiotherapy; (4) international author collaborations based on the coordinates of latitude and longitude on Google Maps. SNA Pajek software was performed in this study.

Results: We found that the top nation is from Australia (409, 9.88\%). The top prominent journal is Aust J Physiother (176, 5.27\%). The Google map combined with SNA to demonstrate the most frequency of authors are from Europe and the two nations of U.K. and Australia.

Conclusions: Google map combined with SNA provides wide and deep insight into the relationships among nations and coauthor collaborations. The results can be provided to readers for the submission to the journal with the aims and the scope related to physiotherapy.
\end{abstract}

\section{Introduction}

Physiotherapy, also called physical therapy, is usually used for treating patient's pain by applying methods such as interferential therapy, ultrasonic, short wave diathermy, wax therapy, and muscle strengthening exercises [1]. In healthcare settings, physiotherapy plays an important role in the recovery of disease patients, especially form them with stroke. It also plays a major role in treating children with cerebral palsy, and in cardiopulmonary rehabilitation [2]. Physiotherapy can be categorized into three main parts including orthopedics, neurophysiotherapy, and cardiorespiratory physiotherapy [3].

As of November 5, 2017, we found 3,342 papers published in journals in a search of a keyword of physiotherapy in paper title from Pubmed.com library. Some issues regarding the most productive journals in physiotherapy and the closest author collaboration in nations are still unclear.

Social Network Analysis (SNA) [4-6] has applied to authorship collaboration in recent years. It is because co-authorship among researchers that forms a type of social network, called co-author network [5]. An apocryphal story often told to illustrate the concept of co-occurrence is about beer and diaper sales. It usually goes along with both beer and diaper sales which were strongly correlated [7-9] in a convenient store. However, how to explore the phenomenon of dual merchandises that are co-existed in a bio-system is still not reported in literature using SNA.

Comorbid is often defined in medicine as existing simultaneously with and usually independently of another medical condition. For instance, torture is associated with adverse health consequences, with especially high rates of Post-Traumatic Stress Disorder (PTSD), depression and chronic pain Cardiovascular comorbidities were common both before and after diabetes [10]. It is very hard to observe the association of two or more symptoms at one moment. In tradition, a disease group was established by applying a relevant health dataset. Each patient was frequency-matched by age, sex, and comorbidities without the study disease from the general population to form a control group. Logistic regression analysis is commonly performed to estimate the influence in use on the disease risk [11]. Whether the SNA can be an alternative to investigate the relation of any pair of dual symptoms is worthwhile to inspect and study.

We are thus interested in using SNA to explore the most pair relations for a medical term of physiotherapy through what we observed and collected from data, such as abstract keywords, coauthor collaborations, and others related to the target term of physiotherapy, especially using Google Maps to present these features.

Our aims are to investigate the target term of physiotherapy with following steps: (1) what nation based on the $1^{\text {st }}$ author published the

Correspondence to: Chun- Ming Yang, Chi-Mei Medical Center, Taiwan, E-mail: gaujang@mail2000.com.tw

Key words: physiotherapy, authorship collaboration, google map, social network analysis, author nation

Received: October 22, 2017; Accepted: November 15, 2017; Published: November 18, 2017 
most papers in physiotherapy in past years; (2) what is the prominent journal that published the most number of papers in physiotherapy; (3) how to transform visual representations from SNA to Google Maps and report the cluster relations in physiotherapy; (4) what different when we show international author collaborations based on the coordinates of latitude and longitude on Google Maps. .

\section{Methods}

\section{Data sources}

We downloaded data including author names, author nations, and the publication journals from the PubMed database (Pubmed.org) maintained by the US National Library of Medicine, National Institutes of Health with the keyword of physiotherapy [Title] on November 5, 2017. Microsoft Excel VBA (visual basic for applications) modules were programed by authors to organize data for the use in this study. A total of 3,342 journal articles were retrieved.

\section{Data arrangement to fit SNA requirement}

Prior to visualize representations of research findings using SNA, we arranged data in compliance with the SNA format and guidelines using Pajek software [12]. Microsoft Excel VBA was applied to make data fitting the SNA requirement. For more information about the data format, see Pajek guideline at http://vlado.fmf.uni-lj.si/pub/ networks/pajek/.

\section{Graphical representations to report}

The most number of papers published by nations and journals: Many article types are categorized on Pubmed.com, we merely extracted these papers of journal article from the library and made tables to present (1) nations based on the $1^{\text {st }}$ author that published the most in physiotherapy, and (2) the prominent journal that published the most number of papers in physiotherapy.

Author nations and their relations: Google Map is suitable for presenting the author-nation distribution on earth by either nation or cluster with coordinates of latitude and longitude. The following two figures were generated to report the clusters of nations on a Google Map, and show international author collaborations based on the coordinates of latitude and longitude on Google Maps.

\section{Statistical tools and data analysis}

SNA Pajek software [12] was used to obtain the measures of centrality. Google map was applied to display visualized representations for the keyword of physiotherapy in title published on Pubmed.com in the past. Author-made Excel VBA modules were prepared for organizing data and matching nations' coordinates of latitude and longitude.

\section{Results}

\section{The most number of papers published by nations and journals}

The most number of papers regarding the keyword of physiotherapy published on Pubmed.com are shown in Table 1 ( $n=2057$ due to some papers without specific nation data on the $1^{\text {st }}$ author). We can see that the top three nations are from Australia (409, 9.88\%), U.K(389, $18.91 \%)$, and Netherlands (128, 6.22\%). Likely, the top three prominent journals are Aust J Physiother (176, 5.27\%), Physiotherapy (168, 5.03\%), and Vopr Kurortol Fizioter Lech Fiz Kult (105, 3.14\%), see Table 2( $\mathrm{n}=3342)$ [Table 1 and 2].

\section{Author nations and their relations}

Authors' nation clusters regarding the keyword of physiotherapy published on Pubmed.com are distributed in Figure 1. We can see that the two nations of U.K. and Australia have the closest relation in comparison with others. Each cluster is colored by the algorithm of community partition in Pajek and sized by the strength of coauthor relations: the stronger, the wider is the connected line. The coordinates have been transformed from the Pajek type (zeros from the left top point to the right bottom) to the Google Map type (zeros at the middle). All nations are relocated according to the coordinates of latitude and longitude in Figure 2. We can see that authors from Europe are frequently found in the field of physiotherapy. Australia, U.S., Canada, and Brazil outside Europe are the top four with the most publication of papers with the keyword of physiotherapy (Figure 1 and 2).

\section{Discussion}

The top three nations are from Australia (409, 9.88\%), U. K (389, $18.91 \%)$, and Netherlands $(128,6.22 \%)$. The top three prominent journals are Aust J Physiother (176, 5.27\%), Physiotherapy (168, 5.03\%), and Vopr Kurortol Fizioter Lech Fiz Kult (105, 3.14\%), (n=3342) (Table 2). This study combined Google map with SNA to demonstrate that the most frequency of authors are from Europe and the two nations of U.K. and Australia have the closest relation in comparison with others.

No any paper has used Google Maps to show international coauthor collaborations for a medical term of physiotherapy. In data analysis, it is very hard to detect the association of two or more symptoms at one time. We applied SNA to explore the relation of any two nations of their coauthors that can be shown a closest collaboration in paper publication. Hyperlinks at references $[13,14]$ are provided to interested readers who can manipulate the Google Maps with the functionalities of zoom-in and zoom-out to know the details of information such as network density of centrality and individual role strength and dominance played in a cluster we provided in this study.

Papers published with a keyword of physiotherapy in Title since 1969 were investigated and a total of 3342 articles were found. If no such Excel modules $[15,16]$ were applied, it is not possible to yield a visual presentation $[13,14]$ used for interpreting the results of the study regarding the international coauthor collaboration related to the keyword of physiotherapy published in the past years in literature.

Many previous researches [4-6] have investigated coauthor collaboration using SNA. However, we have not seen any that can demonstrate a concrete way to show how to conduct this exploration of informative messages to readers. We showed how easy and possible the SNA can display all possible pairs of our observed phenomena at a short time incorporating the free-charged Pajek software with Google Maps. Journal authorship collaboration can be thus compared with each other (Figure 1 and 2). We can see that the author-nation-pattern was the prevailing one which is similar to the previous study [4].

International collaboration in science has increased rapidly in recent decades. One driver of this development has been the efforts of the European Commission to stimulate collaboration within the European Union across sectors and nations [17]. The development also self-organizes at the global level of the United States and other advanced industrial nations for reasons driven by the demands of science. Mass data storage of electronic communications [18] with less expensive travel may also contributes the drivers and facilitators to the author collaboration in science [19]. Some governments [20] even invest purposefully in the stimulation of "internationalization" in 
Table 1. Top 10 Nations whose papers with keyword Physiotherapy in Title across years based on $1^{\text {st }}$ author's nation

\begin{tabular}{|c|c|c|c|c|c|c|c|c|c|c|c|c|c|}
\hline Nation & $<-2007$ & 2008 & 2009 & 2010 & 2011 & 2012 & 2013 & 2014 & 2015 & 2016 & 2017 & Total & $\%$ \\
\hline Australia & 153 & 9 & 19 & 17 & 18 & 19 & 32 & 30 & 23 & 43 & 45 & 409 & 19.88 \\
\hline U.K & 144 & 14 & 20 & 24 & 15 & 26 & 28 & 22 & 25 & 29 & 42 & 389 & 18.91 \\
\hline Netherlands & 60 & 6 & 7 & 3 & 3 & 3 & 11 & 5 & 4 & 11 & 15 & 128 & 6.22 \\
\hline Canada & 34 & 3 & 1 & 10 & 5 & 8 & 7 & 4 & 7 & 12 & 9 & 100 & 4.86 \\
\hline Sweden & 49 & 5 & 3 & 3 & 3 & 3 & 6 & 6 & 6 & 6 & 7 & 97 & 4.72 \\
\hline Brazil & 8 & 3 & 5 & 3 & 8 & 5 & 10 & 5 & 6 & 5 & 6 & 64 & 3.11 \\
\hline Ireland & 14 & 3 & 5 & 4 & 2 & 5 & 4 & 3 & 4 & 5 & 10 & 59 & 2.87 \\
\hline Norway & 15 & 3 & 5 & 2 & 4 & 4 & 5 & 7 & 3 & 7 & 4 & 59 & 2.87 \\
\hline Germany & 19 & 3 & 2 & 4 & 5 & - & 6 & 3 & - & 4 & 9 & 55 & 2.67 \\
\hline U.S & 33 & 3 & 2 & 1 & 1 & 2 & 5 & 1 & - & 2 & 4 & 54 & 2.63 \\
\hline Others & 163 & 36 & 22 & 33 & 37 & 55 & 43 & 58 & 63 & 66 & 67 & 643 & 31.26 \\
\hline 凶凶 & 692 & 88 & 91 & 104 & 101 & 130 & 157 & 144 & 141 & 190 & 218 & 2057 & 100.00 \\
\hline
\end{tabular}

Table 2. Top 10 journals whose papers with keyword Physiotherapy in Title across years

\begin{tabular}{|l|c|c|c|c|c|c|c|c|c|c|c|c|c|}
\hline Journal & $<-2007$ & 2008 & 2009 & 2010 & 2011 & 2012 & 2013 & 2014 & 2015 & 2016 & 2017 & Total & $\%$ \\
\hline Aust J Physiother & 170 & 3 & 3 & - & - & - & - & - & - & - & - & 176 & 5.27 \\
\hline Physiotherapy & 39 & - & 11 & 18 & 13 & 9 & 19 & 12 & 10 & 15 & 22 & 168 & 5.03 \\
\hline Vopr Kurortol Fizioter Lech Fiz Kult & 91 & 5 & 2 & - & 3 & - & 3 & 1 & - & - & - & 105 & 3.14 \\
\hline Physiother Theory Pract & 18 & 6 & 3 & 7 & 3 & 10 & 6 & 8 & 11 & 8 & 17 & 97 & 2.90 \\
\hline Physiother Can & 27 & 3 & 4 & 8 & 3 & 5 & 10 & 7 & 8 & 14 & 4 & 93 & 2.78 \\
\hline Physiother Res Int & 29 & 3 & 2 & 3 & 4 & 2 & 4 & 4 & 3 & 4 & 6 & 64 & 1.92 \\
\hline Disabil Rehabil & 16 & 4 & 2 & 3 & 3 & 2 & 7 & 8 & 6 & 1 & 11 & 63 & 1.89 \\
\hline BMC Musculoskelet Disord & 7 & 4 & 7 & 5 & 1 & 7 & 7 & 8 & 3 & 3 & 6 & 58 & 1.74 \\
\hline Clin Rehabil & 24 & 4 & 4 & 2 & 4 & 1 & 2 & 3 & 2 & 1 & 4 & 51 & 1.53 \\
\hline Man Ther & 19 & 1 & 2 & 4 & 1 & 3 & 6 & 1 & 4 & 7 & - & 48 & 1.44 \\
\hline Others & 1160 & 91 & 80 & 82 & 101 & 120 & 145 & 146 & 143 & 171 & 174 & 2418 & 72.35 \\
\hline Total & 1600 & 124 & 120 & 132 & 136 & 159 & 209 & 198 & 191 & 224 & 244 & 3342 & 100.00 \\
\hline
\end{tabular}

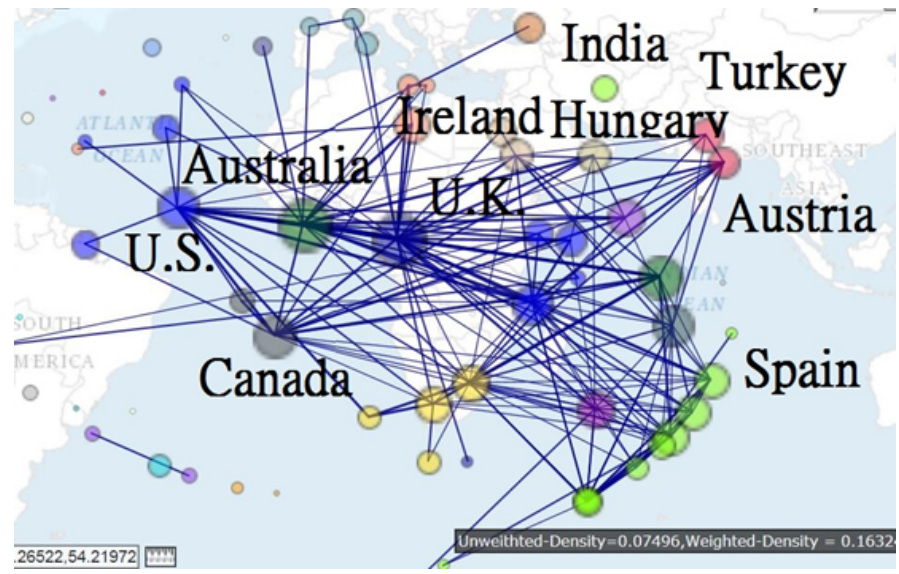

Figure 1. Cluster distribution for nations of $1^{\text {st }}$ author using Pajak coordinates

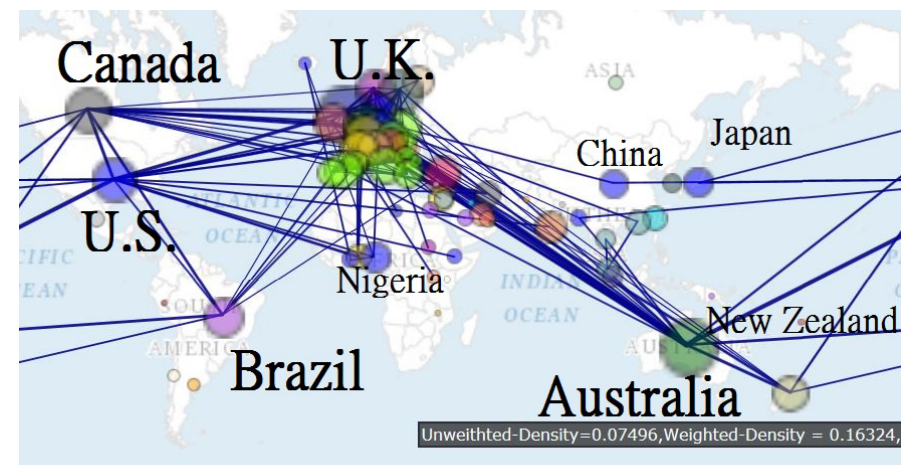

Figure 2. Cluster distribution for nations of $1^{\text {st }}$ author using Google coordinates science to promote the international coauthor collaborations more than ever before.

Since the advent of bibliometrics, citation analysis has been widely used in many disciplines to evaluate the influence of academic articles [21-29]. It is worth using SNA, especially incorporating with Google map, to report journal or topic features in future.

Their some limitations are in this study. Interpretation and generalization of the conclusions of this study should be carried out with caution. First, the data of this study were collected from Pubmed. com. It is worth noting that any attempt to generalize the findings of this study should be made in the similar disciplines and domains with similar topic and scope contexts. Second, although the data were extracted from Pubmed.com and carefully dealt with every linkage as correct as possible, the original downloaded text file including some errors in name of nation because some were not recorded in the context of the downloaded data such as author's nation that might lead to some bias in the results. Third, there are many algorithms used for SNA. We merely applied centrality measure to present the prestigious feature. Any changes made along with algorithm used will present different pattern and judgment. Fourth, the social network analysis is not subject to the Pajeck software we used in this study, Others such as Ucinet [30] and Gephi [31] are suggested to readers for use in future.

\section{Conclusion}

Social network analysis provides wide and deep insight into the relationships among nations, and coauthor collaborations related to the keyword of physiotherapy. The results can be provided to readers for the submission to the journal with the aims and the scope related to physiotherapy. 


\section{References}

1. Dimitrova A, Izov N, Maznev I, Vasileva D, Nikolova M (2017) Physiotherapy Patients with Chronic Obstructive Pulmonary Disease. Open Access Maced J Med Sci 5: $720-723$.

2. Whiteley R, van Dyk N, Wangensteen A, Hansen C (2017) Clinical implications from daily physiotherapy examination of 131 acute hamstring injuries and their association with running speed and rehabilitation progression. Br J Sports Med

3. Ciolac EG, Roberts CK, da Silva JM, Guimarães GV (2014) Age affects exerciseinduced improvements in heart rate response to exercise. Int J Sports Med 35: 371-378 [Crossref].

4. Sadoughi F, Valinejadi A, Shirazi MS, Khademi R (2016) Social Network Analysis of Iranian Researchers on Medical Parasitology: A 41 Year Co-Authorship Survey. Iran J Parasitol 11: 204-212. [Crossref]

5. Osareh F, Khademi R, Rostami MK, Shirazi MS (2014) Co-authorship Network Structure Analysis of Iranian Researchers' scientific outputs from 1991 to 2013 based on the Social Science Citation Index (SSCI). Collnet J Scientometr Info Manag 8: 263271.

6. Liu X, Bollen J, Nelson ML, Van de Sompel H (2005) Co-authorship networks in the digital library research community. Info Process Manag 41: 1462-80.

7. Domingos P (2012) A few useful things to know about machine learning. Communications of the ACM 55: 78-87.

8. Verhoef PC, Kooge E, Walk N (2016) Creating Value with Big Data Analytics: Making Smarter Marketing Decisions. London: Routledge

9. Power DJ (2017) What is the "true story" about data mining, beer and diapers? DSS News. [https://goo.gl/1FtGft]

10. Dibaj I, Overaas Halvorsen J, Edward Ottesen Kennair L, Inge Stenmark H (2017) An evaluation of combined narrative exposure therapy and physiotherapy for comorbid PTSD and chronic pain in torture survivors. Torture 27: 13-27. [Crossref]

11. Lin CW, ChenWK, Hung DZ, Chen YW, Lin CL, et al. (2016). Association between ischemic stroke and carbon monoxide poisoning: a population-based retrospective cohort analysis. Eur J Intern Med 29: 65-70. [Crossref]

12. de Nooy W, Mrvar A, Batagelj V (2011) Exploratory Social Network Analysis with Pajek: Revised and Expanded (2 ${ }^{\text {nd }}$ Edn.) Cambridge University Press. [Crossref]

13. Chien TW. Google Maps on keywords of physiotherapy in journal publication by cluster 2017 http://www.healthup.org.tw/gps/physiotherapy.htm

14. Chien TW. Google Maps on keywords of physiotherapy in journal publication by nation. 2017 http://www.healthup.org.tw/gps/physiotherapy2.htm

15. Chien TW, Shao Y, Jen TW (2017) Development of a Microsoft Excel tool for applying a factor retention criterion of a dimension coefficient to a survey on patient safety culture. Health Qual Life Outcomes 15: 216. [Crossref]
16. Chien TW, Shao Y, Kuo SC (2017) Development of a Microsoft Excel tool for oneparameter Rasch model of continuous items: an application to a safety attitude survey. BMC Med Res Methodol 17: 4 .

17. Glänzel W, Schlemmer B (2007) National research profiles in a changing Europe (1983-2003) An exploratory study of sectoral characteristics in the Triple Helix. Scientometrics 70: 267-275.

18. Barjak F, Eccles K, Meyer ET, Robinson S, Schroeder R (2013) The Emerging Governance of E-Infrastructure. Journal of Computer-Mediated Communication 18: 1-24.

19. Adams J (2012) Collaborations: the rise of research networks. Nature 490: 335-336.

20. Kwon KS, Park HW, So M, Leydesdorff L (2012) Has Globalization Strengthened South Korea's National Research System? National and International Dynamics of the Triple Helix of Scientific Co-Authorship Relationships in South Korea. Scientometrics 90: 163-175.

21. Hu SK, Huang J, Hong WD, Du XJ, Jin R, et al. (2017) The 50 Most-cited Articles in Gastroenterology and Hepatology from Mainland China.Pak J Med Sci 33: 215-220. [Crossref]

22. Coelho DH, Edelmayer LW, Fenton JE (2014) A century of citation classics in otolaryngology-head and neck surgery journals revisited. Laryngoscope 124: 13581362. [Crossref]

23. Baltussen A, Kindler CH (2004). Citation classics in critical care medicine. Intensive Care Med 30: 902-910. [Crossref]

24. Brandt JS, Downing AC, Howard DL, Kofinas JD, Chasen ST (2010) Citation classics in obstetrics and gynecology: the 100 most frequently cited journal articles in the last 50 years. Am J Obstet Gynecol 203:355 1-7. [Crossref]

25. O'Sullivan KE, Kelly JC, Hurley JP (2015) The 100 most cited publications in cardiac surgery: a bibliometric analysis. Irish J Med Sci 184: 91-99. [Crossref]

26. Kelly JC, Glynn RW, O'Briain DE, Felle P, McCabe JP (2010) The 100 classic papers of orthopedic surgery: a bibliometric analysis. J Bone Joint Surg $\mathrm{Br}$ 92: 1338-134. [Crossref]

27. Kavanagh RG, Kelly JC, Kelly PM, Moore DP (2013) The 100 classic papers of pediatric orthopaedic surgery: a bibliometric analysis. J Bone Joint Surg Am 95:134. [Crossref]

28. Pagni M, Khan NR, Cohen HL, Choudhri AF (2014) Highly cited works in radiology: the top 100 cited articles in radiologic journals. Acad Radiol 21: 1056-1066.[Crossref]

29. Cao F, Li J, Li A, Fang Y, Li F (2012) Citation classics in acute pancreatitis. Pancreatology 12: 325-330. [Crossref]

30. Borgatti SP, Everett MG, Freeman LC (2002) Ucinet for Windows: Software for Social Network Analysis. Harvard, MA: Analytic Technologies.

31. Bastian M, Heymann S, Jacomy M (2009) Gephi: an open source software for exploring and manipulating networks. International AAAI Conference on Weblogs and Social Media.

Copyright: $\odot 2017$ Chien TW. This is an open-access article distributed under the terms of the Creative Commons Attribution License, which permits unrestricted use, distribution, and reproduction in any medium, provided the original author and source are credited. 